\title{
Prevalence and risk factors for dysmenorrhoea among nursing student and its impact on their quality of life
}

\author{
Shashikala Karanth ${ }^{1 *}$, S. R. Liya ${ }^{2}$ \\ ${ }^{1}$ Department of Obstetrics and Gynecology, St Johns Medical College and Hospital, Bengaluru, Karnataka, India \\ ${ }^{2}$ Department of Obstetrics and Gynecology, Loudes Matha Hospital Pacha, Alappuzha, Kerala, India
}

Received: 30 May 2018

Accepted: 04 June 2018

*Correspondence:

Dr. Shashikala Karanth,

E-mail: dr.shashikaranth@gmail.com

Copyright: $\odot$ the author(s), publisher and licensee Medip Academy. This is an open-access article distributed under the terms of the Creative Commons Attribution Non-Commercial License, which permits unrestricted non-commercial use, distribution, and reproduction in any medium, provided the original work is properly cited.

\begin{abstract}
Background: Dysmenorrhea is an important health problem of adolescent girls, that affects their quality of life and it is one of the leading causes of repeated school absenteeism. The purposes of this study was to determine the prevalence and risk factors for dysmenorrhea among nursing students and its impact on their quality of life.

Methods: A prospective study was carried out in St Johns Nursing College, Bengaluru.200 nursing students aged between 18-20 years were included. Standardized questionnaires were used to obtain relevant data. Data was analysed using Chi-sq. test, correlation and regression analysis by SPSS version 23.

Results: The prevalence of dysmenorrhea was $62.5 \%$. The mean age, age at menarche and, the mean PABC of the students were $18.7 \pm 0.48,13.3 \pm 1.20$ and $74.96 \pm 16.14$ respectively, which is not significant. The average length of menstrual cycle was between 28-30 days, duration of bleeding as 3-5 days. Duration of sleep, regular menstrual cycle and low BMI exhibited positive correlation $(\mathrm{p}<0.05)$ while Family history and exercising habits did not exhibit significant effect. Dysmenorrhea was significantly associated with repeated school absenteeism (16\%).

Conclusions: Dysmenorrhoea is found to be highly prevalent among nursing students and is one of the leading causes of absenteeism. Regular cycle, duration of sleep and low BMI were significant risk factors for dysmenorrhea. Findings of present study suggest the need for educating adolescent girls on appropriate and effective management of dysmenorrhea.
\end{abstract}

Keywords: Adolescents, Body mass index (BMI), Dysmenorrhoea

\section{INTRODUCTION}

Dysmenorrhoea is one of the most common health problems in young adolescent girls as it affects $50-90 \%$ of the general population. ${ }^{1}$ Dysmenorrhea refers to a cyclical lower abdominal or pelvic pain which may radiate to the back or to the thighs, occurring during menstruation often accompanied by other biological symptoms including dizziness, fatigue, sweating, backache, headache, nausea, vomiting, and diarrhoea.

It is divided into two types: Primary dysmenorrhea and secondary dysmenorrhea. Primary dysmenorrhea is the one, in which there is cramping pain in the lower abdomen at the onset of menstruation in the absence of any identifiable pelvic disease Secondary dysmenorrhea is a menstrual pain associated with underlying pathology and its onset might be years after menarche. ${ }^{2}$ The prevalence of dysmenorrhoea among young women varies widely from country to country. A recent study on dysmenorrhea showed that there are different prevalence rates among females in different countries and different associated factors with dysmenorrhea or severity of pain. ${ }^{3}$ Previous studies on university students showed its prevalence to be $34 \%$ in Egypt, $64 \%$ in Nigeria and Mexico, $84 \%$ in Thailand $88 \%$ in Turkey and $93 \%$ in 
Taiwan, $74.5 \%$ in Malaysia, $70 \%$ in Italy, $80 \%$ in Australia, $85 \%$ among Hispanic, and Lowest prevalence has been reported in Japan (16\%). ${ }^{3-13}$ True incidence and prevalence of dysmenorrhea are not clearly established in India. Studies from various parts of India reported the prevalence of dysmenorrhoea ranges between 50 to $87.8 \% .{ }^{14-19}$ Several studies reported that various physiological, cultural, and psychological factors are involved in dysmenorrhea. Reported risk factors for dysmenorrhea include earlier age at menarche, longer menstrual periods, heavier menstrual flow, family history of dysmenorrhea, and reduced frequency of breakfast meals per week and low BMI. ${ }^{20-23}$ Dysmenorrhea is an important public health problem among university students and is associated with school absenteeism and poor quality of life. Approximately $10-15 \%$ of females experience monthly menstrual pain severe enough to stop normal daily functions at work, home, or school. ${ }^{19,24,25,26}$ Data from various studies conducted earlier show that absenteeism from school due to primary dysmenorrhea is $34-50 \% .^{27,28}$ Due to its importance, different treatments like pharmacological and non-pharmacological treatment approaches such as nonsteroidal anti-inflammatory drugs (NSAIDS), herbal, dietary therapies, yoga, meditation, and acupuncture have been tried to decrease the effects of dysmenorrhea. $^{29}$ The purpose of this study was to determine the prevalence and risk factors for dysmenorrhea in nursing students and its impact on their quality of life. This study is also assessing the relationship between Body mass index (BMI) and dysmenorrhoea among these students.

\section{METHODS}

The study was carried out in St Johns Nursing College, Bengaluru, Karnataka, India. It was a prospective study, which included 200 nursing students of the age group 1820 years. A self-administered questionnaire was distributed to all the participants. Participation by students was strictly voluntary. Informed consent was taken from all the students before their participation. The socio-demographic and lifestyle characteristics of the students were collected through standard questionnaire which included age, parent's education, family history of dysmenorrhoea, regularity of the cycle, menorrhagia, anaemia, exercise habits, sleeping habits, past history, medication use, area of residence (Rural/urban). Intensity of pain was assessed by the Multidimensional Scoring System of Andersch and Milsom which defines pain as, Mild dysmenorrhea is defined as painful menstruation with no limitation of normal activity, with infrequent requirement of analgesics and no systemic complaints. ${ }^{30}$

Moderate dysmenorrhea is defined as menstrual pain affecting daily activities, with requirement of analgesics for pain relief and few systemic complaints. Severe dysmenorrhea is defined as menstrual pain with severe limitation of daily activities, poor response to analgesics, and apparent systemic complaints like vomiting, fainting. According to the pictorial blood loss assessment charts
(PBAC) where score of 100 at the end of menses was considered equivalent to $80 \mathrm{ml}$ blood loss and a score $>100$ was considered as menorrhagia. ${ }^{31}$ BMI was calculated by weight in $\mathrm{kg}$ divided by the square of height in meter. The students were classified into four groups: underweight (<18.5), normal (18.5-24.99), overweight (25-29.99) or obese $(\geq 30)$ based on the recommendations from the World Health Organization (WHO).

\section{Statistical Methods}

Descriptive statistics were reported using mean and standard deviation for the continuous variables, number and percentages for the categorical variables. Chi-square test was used to test the association between demographic and clinical characteristics with the presence of dysmenorrhea. Logistic regression was used to find the factors associated with the presence of dysmenorrhea. $\mathrm{P}$ value less than 0.05 was considered as statistically significant. All the analyses were done using SPSS version 23.0.

\section{RESULTS}

Table 1: Characteristics of the Study Subjects.

\begin{tabular}{|llll|}
\hline Factors & & Frequencies & $\%$ \\
\hline Age & 17 & 3 & 1.5 \\
\hline & 18 & 49 & 24.5 \\
\hline Residence & 19 & 148 & 74.0 \\
\hline & Rural & 72 & 36 \\
\hline Sleep hours & Urban & 128 & 64 \\
\hline & $<8$ & 138 & 9.0 \\
\hline Dysmenorrhoea & Yes & 125 & 31.0 \\
\hline & No & 75 & 62.5 \\
\hline Regularity & Regular & 19 & 37.5 \\
\hline & Irregular & 181 & 9.5 \\
\hline Effect of media & Radio & 5 & 90.5 \\
\hline & TV & 120 & 2.5 \\
\hline & TV+Radio & 75 & 60.0 \\
\hline Exercise habit & Mild & 150 & 37.5 \\
\hline & Moderate & 50 & 75.0 \\
\hline SES & L & 4 & 25.0 \\
\hline & M & 177 & 2.0 \\
\hline & H & 19 & 88.5 \\
\hline BMI category & Normal & 116 & 9.5 \\
\hline & Underweight & 46 & 58.0 \\
\hline School absent & Overweight & 38 & 23.0 \\
\hline Family history & & 32 & 19.0 \\
\hline present & & 36 & 16.0 \\
\hline Pallor & & 16 & 18.0 \\
\hline
\end{tabular}

Table 1 describes the characteristics of the study subjects. The mean age and age at menarche of the students studied was $18.7 \pm 0.48$ and $13.3 \pm 1.20$ respectively. Menorrhagia was defined in present study, according to the pictorial blood loss assessment charts (PBAC) where 
score of 100 at the end of menses was considered equivalent to $80 \mathrm{ml}$ blood loss and a score $>100$ was considered as menorrhagia. The mean PABC of the students was $74.96 \pm 16.14$ which is not significant. The mean calorie intake per day of the students was $2071 \pm 233$. The proportion dysmenorrhea reported was $62.5 \%$. There was no significant difference in the mean age, age at menarche, calorie intake of the students and amount of the bleeding between the presence of dysmenorrhea and the absent group.
The average length of menstrual cycle was between 2830 days, which $87 \%$ of the students reported. Nearly two third of the students reported their duration of bleeding as 3-4 days to 4-5 days. Comparison of demographic and other parameters by the presence of dysmenorrhea is given in Table 2.

Table 2: Comparison of demographic and clinical characteristics by presence/absence of dysmenorrhea.

\begin{tabular}{|c|c|c|c|}
\hline Factor & & Dysmenorrhea-Yes & Dysmenorrhea -No \\
\hline \multirow[t]{3}{*}{ Age } & 17 & $2(1.6)$ & $1(1.3)$ \\
\hline & 18 & $31(24.8)$ & $18(24.0)$ \\
\hline & 19 & $92(73.6)$ & $56(74.7)$ \\
\hline \multirow[t]{2}{*}{ Residence } & Rural & $51(40.8)$ & $21(28.0)$ \\
\hline & Urban & $74(59.2)$ & $54(72.0)$ \\
\hline \multirow[t]{2}{*}{ Sleep Hours } & $<8$ & $80(64.0) *$ & $58(77.3)$ \\
\hline & $>8$ & $45(36.0)$ & $17(22.7)$ \\
\hline \multirow[t]{2}{*}{ Regularity of cycle } & Regular & $8(6.4) *$ & $11(14.7)$ \\
\hline & Irregular & $117(93.6)$ & $64(85.3)$ \\
\hline \multirow[t]{3}{*}{ Effect of media } & Radio & $3(2.4)$ & $2(2.7)$ \\
\hline & TV & $75(60.0)$ & $45(60.0)$ \\
\hline & TV+Radio & $47(37.6)$ & $28(37.3)$ \\
\hline \multirow{2}{*}{ Exercise habit } & Mild & $92(73.6)$ & $58(77.3)$ \\
\hline & Moderate & $33(26.4)$ & $17(22.7)$ \\
\hline \multirow[t]{3}{*}{ SES } & $\mathrm{L}$ & $3(2.4)$ & $1(1.3)$ \\
\hline & M & $110(88.0)$ & $67(89.3)$ \\
\hline & $\mathrm{H}$ & $12(9.6)$ & $7(9.3)$ \\
\hline \multirow[t]{3}{*}{ BMI category } & Normal & $84(67.2)$ & $55(73.3)$ \\
\hline & Underweight & $35(28.0)^{*}$ & $11(14.7)$ \\
\hline & Overweight & $6(4.8)$ & $9(12.0)$ \\
\hline Family history present & & $25(20.0)$ & $11(14.7)$ \\
\hline Pallor & & $9(7.2)$ & $7(9.3)$ \\
\hline Mood changes/tiredness & & 2 & 0 \\
\hline Associated other pain & & $81(64.8)^{*}$ & $39(52.0)$ \\
\hline Medicines taken & & $31(24.8)$ & $10(13.3)$ \\
\hline Heat application & & $30(24.0)$ & $11(14.7)$ \\
\hline Lying & & $98(78.4)^{*}$ & $36(48.0)$ \\
\hline Exercise & & $50(40.0)$ & $27(36.0)$ \\
\hline Food & & $22(17.6)$ & $6(8.0)$ \\
\hline Temperature & & $19(15.2)^{*}$ & 0 \\
\hline Tension & & $49(39.2)$ & $24(32.0)$ \\
\hline School Absent & & $25(20.0)^{*}$ & $7(9.3)$ \\
\hline
\end{tabular}

Reported as number and \%* -p $<0.05$ using chi-square test

Duration of sleep, regularity of menstrual cycle was significantly associated with the presence of dysmenorrhea. Students who had sleep less than 8 hours and regular menstrual cycles were associated with the presence of dysmenorrhea.
BMI category was significantly associated with the presence of dysmenorrhea. Underweight students were significantly associated than normal and overweight students $(p<0.05)$. Exercising habits have no significant correlation with dysmenorrhea. Besides, the presence of dysmenorrhea was significantly associated with increased school absenteeism. In present study, we analysed the 
various components which improve or aggravate the complaints related to dysmenorrhea (Table 3). Lying down/relaxing showed improvement in $78.4 \%$ of the population which proved to be the most effective measure, followed by tablets and heat/pressure.

There was not much significant change with the use of injections to relieve the symptoms of dysmenorrhea. Tension caused aggravation in an average of $40 \%$ of patients; Movements also caused increased symptoms in nearly $40 \%$ of patients and temperature/food in $15 \%$ of patients.

\section{Table 3: Factors which aggravates/relieves} dysmenorrhic pain.

\begin{tabular}{|ll|l|}
\hline Factors & Frequencies & Percentage \\
\hline Mood changes/tiredness & 2 & 0 \\
\hline Associated other pain & 120 & 60.0 \\
\hline Medicines taken & 41 & 20.5 \\
\hline Heat application & 41 & 20.5 \\
\hline Lying & 67 & 67.0 \\
\hline Exercise & 77 & 38.5 \\
\hline Food & 28 & 14.0 \\
\hline Temperature & 26 & 13.0 \\
\hline Tension & 73 & 36.5 \\
\hline
\end{tabular}

\section{DISCUSSION}

Prevalence of dysmenorrhoea in present study is $62 \%$ (Figure 1). This observation is consistent with previous studies from India and other countries. ${ }^{4-19}$ An Egyptian study reported very high prevalence (94\%) of dysmenorrhea among nursing students. ${ }^{32}$

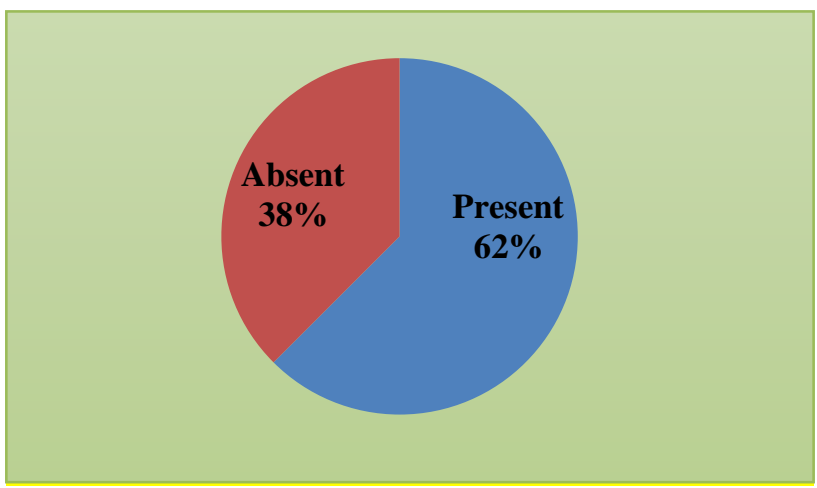

Figure 1: Distribution of dysmenorrhea.

In present study age of the students, family history, age of menarche, parent's educational status, menorrhagia, effect of media on their attitude towards dysmenorrhoea, socioeconomic status and anaemia did not exhibit significant association with dysmenorrhoea. Similar findings have been reported in the literature with respect to a negative correlation with development of dysmenorrhoea. ${ }^{15,33}$ Length of menstrual cycle and duration of menses were found to be associated with dysmenorrhea. In China, the increased menstrual flows have been reported to be associated with an increase in the severity of dysmenorrhea. ${ }^{34,35}$ Present study showed that the students who had regular menstrual cycles are more closely associated with the presence of dysmenorrhea ( $\mathrm{p}$-value 0.054). A study by William et al had explained the association between dysmenorrhoea and regular cycle. ${ }^{36}$ The Study by Kural $M$ et al did not find the association between length of cycle and dysmenorrhea. ${ }^{37}$

Majority of the girls in present study were found to have low BMI indicating the poor nutritional status among our students. In present study, the relation between dysmenorrhea and BMI was found to be significant ( $p$ value $<0.05$ ) with increased prevalence of dysmenorrhea in the low BMI group (Figure 2).

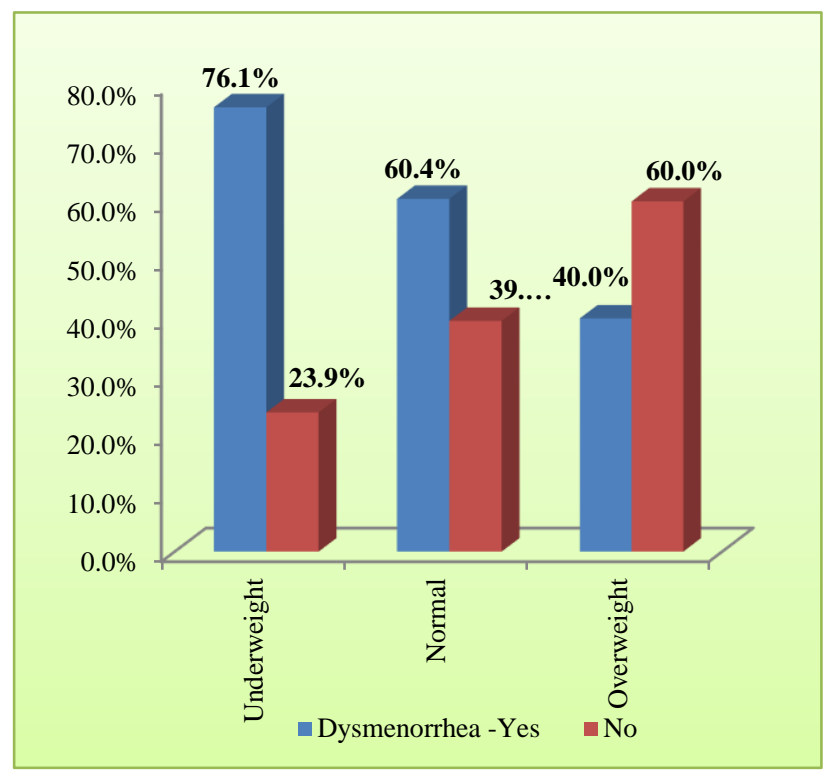

Figure 2: Distribution of BMI

Our results are supported by the study of Tangchai et al, Hirata et al, and Chauhan M, and disagrees with Ibrahim NK et al study. ${ }^{6,38,39,40}$ In contrast to present study overweight was an important risk factor for dysmenorrhea in Harlow et al study. ${ }^{41}$ A longitudinal study by $\mathrm{Ju}$ et al. reported that U-shaped association between dysmenorrhea and BMI, revealing increased prevalence in both underweight and overweight. ${ }^{42}$

In present study we observed that dysmenorrhoea had its impact on the daily activities of the students leading to inability to attend classes, inability to pursue routine activities and hobbies. Students had symptoms severe enough to cause absenteeism from college and classes. The school absenteeism rate in present study (16\%) was lower than that reported by Hillen et al (45.6-54\%). ${ }^{12}$ Reported rates of absenteeism from other studies ranged from 24 to $50 \% .4,9,12,13,43,44$ These results revealed that during dysmenorrhea students may face a tremendous impact in their educational outcomes and daily activities. In present study $64 \%$ of the students with dysmenorrhea 
had less than 8 hours of sleep and $36 \%$ of the students had more than 8 hours of sleep. Hence the relation between dysmenorrhea and sleeping habits were found to be highly significant ( $p$ value=0.048). A study by Gebeyehu M B nearly half $(42.7 \%)$ of the students reported they had decreased appetite and altered sleeping pattern. ${ }^{34}$ Many studies reported that participants had disturbed or altered pattern of sleep due to dysmenorrhoea. So far none of the studies reported the relationship between the duration of sleep and dysmenorrhoea. This association could be due to negative effect of increased physical activity.

Exercise works by improving blood flow at the pelvic level as well as stimulating the release of endorphins, which act as non-specific analgesics. Present study showed that there is no association between exercise and dysmenorrhea, this observation corroborates with Omidvar S study. ${ }^{19}$ Study conducted by Madhubala et al and Mahvash $\mathrm{N}$ et al showed that increased physical activity was found to be significantly associated with decreasing intensity of dysmenorrhea. ${ }^{39,29}$

It is worthwhile to comment that, despite the sufferings, only a small proportion of girls had sought pharmacological management $(21 \%)$ and $79 \%$ depended on non-pharmacological methods in present study. Only $14.2 \%$ had sought medical advice and this suboptimal use of the medical advice has been reported by others. ${ }^{3,12,19}$ Approaches to deal with dysmenorrhoea differ in different cultures. According to the study from Mexico, $62 \%$ of university students with dysmenorrhoea selfmedicated while, $26 \%$ consulted physicians. $^{5}$

Pain relieving factors lying down/relaxing showed improvement in $78.4 \%$ of the students, which proved to be the most effective measure, followed by tablets and heat/pressuring in present study. There was not much significant change with the use of injections to relieve the symptoms of dysmenorrhea. Present study corresponds to the study by Kamonsak Tangchai included, use of heat pad in 34\%, use of analgesics (Paracetamol, Aspirin and Ibuprofen) in $32.5 \%$ cases. ${ }^{6,34}$ According to the Swanberg and Ulmsten $23 \%$ use analgesics and $34 \%$ prefer lying down/relaxing to relieve dysmenorrhea. ${ }^{44}$ A study by Hillens most common medication used by those reporting dysmenorrhea was simple analgesics (53\%), followed by nonsteroidal anti-inflammatory drugs (NSAIDs). ${ }^{11}$ According to the Gebeyehu MB study about $36.3 \%$ use analgesics, Ibuprofen (12.6\%), diclofenac (6.9\%), and paracetamol $(5.4 \%)$ were the most frequently used medications, whereas coffee, tea, and Coca-Cola $(34.4 \%)$, and heat therapy $(3.9 \%)$ were the most frequently used home remedies to manage their illness. ${ }^{34}$

\section{CONCLUSION}

Prevalence of dysmenorrhea in present study is high.Regular menstrual cycle, low BMI, duration of sleep (less than 8hours) are the risk factors for dysmenorrhea in present study. Dysmenorrhea has a negative effect on health-related quality of life. It is a leading cause of school and college absenteeism.

Attempt should be made to find out the factors, which cause dysmenorrhoea, and it is necessary for us to clarify these factors to improve their quality of life. Appropriate counselling and management should be instituted among the students to improve their academic performance. Information, education and support should also be extended to parents, school peer leaders, and hostel administrators in order to address the reproductive health needs to prevent unnecessary suffering of the student during menstruation.

\section{ACKNOWLEDGMENTS}

The authors are extending their sincere thanks to the Principal, Teachers and Nursing Students of St. Johns Nursing College for their cooperation.

Funding: No funding sources

Conflict of interest: None declared

Ethical approval: The study was approved by the Institutional Ethics Committee

\section{REFERENCES}

1. Margaret A, Manjubala D. Relationship between BMI (body mass index) and dysmenorrhea among adolescents in a college of nursing at Puducherry, India. Int Res J Med Sci. 2016;4(3):4-6.

2. Berek JS. Berek and Novak's Gynecology. $15^{\text {th }}$ ed. Philadelphia: Lippincott, Williams and Wilkins; 2011

3. De Sanctis V, Soliman AT, Elsedfy H, Soliman NA, Soliman R, El Kholy M. Dysmenorrhea in adolescents and young adults: a review in different country. Acta Biomed. 2017;87(3):233-46.

4. Titilayo A, Agunbiade OM, Banjo O, Lawani A. Menstrualdiscomfort and its influence on daily academic activities and psychosocial relationship among undergraduate female students in Nigeria. Tanzan J Health Res. 2009;11:181-8

5. Ortiz MI. Primary dysmenorrhea among Mexican university students: prevalence, impact and treatment. Eur J Obstet Gynecol Reprod Biol. 2010;152:73-7

6. Tangchai K, Titapant V, Boriboonhirunsarn D. Dysmenorrhea in Thai adolescents: prevalence, impact and knowledge of treatment. J Med Assoc Thai. 2004;87(3):S69-73.

7. Polat A, Celik H, Gurates B, et al. Prevalence of primary dysmenorrhea in young adult female university students.Arch Gynecol Obstet 2009;279:527-32.

8. Cheng HF, Lin YH. Selection and efficacy of selfmanagement strategies for dysmenorrhea in young Taiwanese women. J Clin Nurs. 2011;20:1018-25 
9. Wong LP, Khoo EM. Dysmenorrhea in a multiethnic population of adolescent Asian girls. Int J Gynecol Obstet. 2010;108(2):139-42.

10. Rigon F, De Sanctis V, Bernasconi S, Bianchin L, Bona $\mathrm{G}$, Bozzola $\mathrm{M}$, et al. Menstrual pattern and menstrual disorders among adolescents: an update of the Italian data. Ital J Pediatra. 2012;38:38.

11. Nohara M, Momoeda M, Kubota T, Nakabayashi M. Menstrual cycle and menstrual pain problems and related risk factors among Japanese female workers, Ind Health, 2011;492:228-34).

12. Hillen TI, Grbavac SL, Johnston PJ, Straton JA, Keogh JM. Primary dysmenorrhea in young western Australian women: prevalence, impact, and knowledge of treatment. J Adolesc Health. 1999; 25(1):40-5.

13. Banikarim C, Chacko MR, Kelder SH. Prevalence and impact of dysmenorrhea on Hispanic female adolescents. Arch Pediatr Adolesc Med. 2000; 154(12):1226-29.

14. George A, Bhaduri A., Dysmenorrhea among adolescent girls-symptoms experienced during menstruation. Health Promotion Educ. 2002; 17:4.

15. Patel V, Tanksale V, Sahasrabhojanee M, Gupte S, Nevrekar P. The burden and determinants of dysmenorrhea: A population-based survey of 2262 women in Goa, India. BJOG. 2006;113:453-63.

16. Nair P.G.V., Kannan A. Awareness and practices of menstruation and pubertal changes amongst unmarried female adolescents in a rural area of East Delhi. IJCM;32(2):156-7.

17. Singh AK, Singh HD, Nel B, Singh P, Tiwari P. Prevalence and severity of dysmenorrhea: A problem related to menstruation, among first and second year female medical students. Indian J Physiol Pharmacol. 2008;52(4):389-97.

18. Agarwal AK, Agarwal A. A study of dysmenorrhea during menstruation in adolescent girls. Indian $\mathrm{J}$ Comm Med: Official Pub Indian Ass Prevent Social Med. 2010;35(1):159-64.

19. Omidvar S, Bakouei F, Amiri FN, Begum K. Primary Dysmenorrhea and Menstrual Symptoms in Indian Female Students: Prevalence, Impact and Management; Global J Health Sci. 2016:8(8):135-44

20. Salmalian H, Saghebi R, Moghadamnia AA, Bijani A, Faramarzi M, Nasiri Amiri F, et al. Comparative effect of thymus vulgaris and ibuprofen on primary dysmenorrhea: A triple-blind clinical study. Caspian J Intern Med. 2014;5:82-8

21. Eittah HF. Effect of breakfast skipping on young females' menstruation. Health Sci J. 2014;8(4):46984.

22. Gibbs RS, Karlan BY, Haney AF, Nygaard IE. Danforth's Obstetrics and Gynecology. 10th ed. Philadelphia: Lippincott, Williams and Wilkins; 2008. 9.

23. Schuiling KD, Likis FE. Women's Gynecologic Health. $2^{\text {nd }}$ ed. Massachusetts: Jones and Bartlett Learning; 2011.
24. Ahuja A, Sharma MK, Singh A. Impact of dysmenorrhea on quality of life of adolescent girls of Chandigarh. Journal of Child and Adolescent Behavior. 2016;

25. Unsal A, Ayranci U, Tozun M, Arslan G, Calik E. Prevalence of dysmenorrhea and its effect on quality of life among a group of female university students. Ups J Med Sci. 2010; 115(2):138-45.

26. Sharma N., Sagayaraj M., Sujatha B. Menstrual characteristics and prevalence of dysmenorrhea in college students. Int J Sci Res Pub. 2014;4(10):1-6.

27. Barnard K, Frayne SM, Skinner KM, Sullivan LM. Health status among women with menstrual symptoms. J Womens Health (Larchmt). 2003;12(9):911-9.

28. Bettendorf B, Shay S, Tu F. Dysmenorrhea: Contemporary perspectives. Obstet Gynecol Surv. 2008;63(9):597-603.

29. Mahvash N, Eidy A, Mehdi K. The effect of physical activity on primary dysmenorrhea of female university students. World Applied Sci J. 2012;17(10):1246-52.

30. Larroy C. Comparing visual-analog and numeric scales for assessing menstrual pain. Behav Med. 2002;27:179-81

31. Higham JM, O'brien PM, Shaw R. Assessment of menstrual blood loss using a pictorial chart. BJOG: An Int J Obstet Gynaecol. 1990;97(8):734-9.

32. El-Hameed NA, Mohamed MS, Ahmed NH, Ahmed ER. Assessment of dysmenorrhea and menstrual hygiene practices among adolescent girls in some nursing schools at EL-Minia governorate, Egypt. J American Sci. 2011;7(216):223.

33. Santina T, Wehbe N, Ziade F. Exploring dysmenorrhoea and menstrual experiences among Lebanese female adolescents. East Mediterr Health J. 2012;18(8):857-63.

34. Gebeyehu MB, Mekuria AB, Tefera YG, Andarge DA, Debay YB, Bejiga GS, et al. Prevalence, Impact, and Management Practice of Dysmenorrhea among University of Gondar Students, North western Ethiopia: A Cross-Sectional Study. International Journal of Reproductive Medicine. 2017;2017

35. Zhou HG, Yang ZW. Prevalence of dysmenorrhea in female students in a Chinese university: A prospective study. Health. 2010;2(4):311-4.

36. Willman EA, Collins WP, Clayton SG. Studies in the involvement of prostaglandins in uterine symptomatology and pathology. $\mathrm{Br} \quad \mathrm{J}$ Obstet Gynaecol. 1976;83(5):337-41

37. Kural M, Noor NN, Pandit D, Joshi T, Patil A Menstrual characteristics and prevalence of dysmenorrhea in college going girls. J Family Med Prim Care. 2015;4(3):426-31.

38. Hirata M, Kumabe K, Inove Y. Study of relation between frequency of menstrual pain and body weight in female adolescents. Japanese J Public Health. 2002;49:516-24.

39. Chauhan M, Kala J. Relation between dysmenorrhea and body mass index in adolescents with rural versus 
urban variation. J Obstet Gynaecol India. 2012; 62:442-5.

40. Ibrahim NK, AlGhamdi MS, Al-Shaibani AN, AlAmri FA, Alharbi HA, Al-Jadani AK, et al. Dysmenorrhea among female medical students in King Abdulaziz University: Prevalence, Predictors and outcome. Pak J Med Sci. 2015;31(6):1312..

41. Harlow SD, Park M. A longitudinal study of risk factors for the occurrence, duration and severity of menstrual cramps in a cohort of college women. Br J Obstet Gynaecol. 1996;103:1134-42.

42. Ju H, Jones M, Mishra GD. A U-shaped relationship between body mass index and dysmenorrhea: A longitudinal study. PLoS One 2015;10(7):e0134187.
43. Chia CF, Lai JH, Cheung PK, Kwong LT, Lau FP, Leung KH, Leung MT, Wong FC, Ngu SF. Dysmenorrhoea among Hong Kong university students: prevalence, impact and management. Hong Kong Med J. 2013;19:222-8

44. Svanberg L, Ulmsten U. The incidence of primary dysmenorrhea in teenagers. Arch Gynecol. 1981;230(3):173-7.

Cite this article as: Karanth S, Liya SR. Prevalence and risk factors for dysmenorrhoea among nursing student and its impact on their quality of life. Int $\mathbf{J}$ Reprod Contracept Obstet Gynecol 2018;7:2661-7. 